\title{
Serotonergic antidepressants' effects on bone health
}

\author{
Autumn Walkerly, PharmD, BCPS, and Chris Paxos, PharmD, BCPP, BCPS, BCGP
}

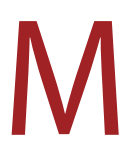

rs. D, age 67 , has a history of major depressive disorder. She has had adequate treatment trials with duloxetine, mirtazapine, and sertraline; each failed to produce remission. She is currently prescribed paroxetine, $40 \mathrm{mg} / \mathrm{d}$, and aripiprazole, $10 \mathrm{mg} / \mathrm{d}$, with good efficacy. She also has a history of hypertension and seasonal allergies, for which she receives amlodipine, $10 \mathrm{mg} / \mathrm{d}$, and loratadine, $10 \mathrm{mg} / \mathrm{d}$, respectively.

Mrs. D's depressive symptoms were well controlled until 2 months ago, when she fell and fractured her hip. With encouragement from her prescriber, she enrolled in a partial hospitalization program for more intensive psychotherapy. During a medication education session, she is surprised to learn that antidepressants may affect bone health.

During a medication management meeting with her prescriber, Mrs. D asks about the risk of osteoporosis, and whether her antidepressant could have contributed to her hip fracture.

Bone is a dynamic tissue that undergoes a continuous process of remodeling. Osteoblasts are responsible for bone formation, whereas osteoclasts are responsible for bone resorption. Osteocytes-the

Dr. Walkerly is a PGY-2 Psychiatric Pharmacy Resident, Michigan Medicine, Ann Arbor, Michigan. Dr. Paxos is Professor, College of Pharmacy, and Associate Professor, College of Medicine, Northeast Ohio Medical University, Rootstown, Ohio.

Disclosures

The authors report no financial relationships with any companies whose products are mentioned in this article, or with manufacturers of competing products.

doi: $10.12788 /$ cp. 0162 predominant cell type in bone-along with cytokines, hormones, and growth factors help to orchestrate these actions. ${ }^{1}$ Serotonin is increasingly recognized as a factor in bone homeostasis. Bone synthesizes serotonin, expresses serotonin transporters, and contains a variety of serotonin receptors. ${ }^{2}$

Serotonin serves many physiologic functions outside of the CNS, and it appears to have opposing actions on bone metabolism (Table 1,1,3 page 46). Peripheral (gutderived) serotonin inhibits bone formation through its effects on osteoblasts, whereas the actions of serotonin in the CNS promote bone growth through inhibitory effects on sympathetic output. ${ }^{2}$ Selective serotonin reuptake inhibitor (SSRI) enhancement of

\section{Practice Points}

- Central and peripheral actions of serotonin on bone result in positive and negative effects on bone formation, respectively.

- The risk of fracture is likely multifactorial, and includes risk from serotonergic antidepressant use and from depression. The extent to which selective serotonin reuptake inhibitors (SSRIs) are responsible for fracture risk is unknown.

- In vitro SSRI data suggest sertraline may adversely affect bone the most, followed by fluoxetine, paroxetine, fluvoxamine, and citalopram; however, the implications for clinical care are unclear and require more investigation.

- Educate patients on modifiable risk factors and discuss calcium and vitamin D requirements, diet, and exercise.

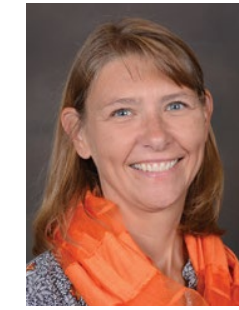

Vicki L. Ellingrod, PharmD, FCCP Department Editor
Savvy Psychopharmacology is produced in partnership with the College of Psychiatric and Neurologic Pharmacists cpnp.org mhc.cpnp.org (journal) 


\section{Clinical Point}

\section{Central and peripheral actions of serotonin on bone result in positive and negative effects on bone formation, respectively}

Discuss this article at www.facebook.com/ MDedgePsychiatry

\section{Range of physiological function of serotonin and selected receptor locations}

peripheral serotonin and its negative effect on bone may outweigh the benefits caused by SSRI enhancement of central serotonin neurotransmission. ${ }^{1}$ In vitro data suggest SSRIs inhibit osteoblast and osteoclast function, theoretically decreasing bone turnover and increasing fracture risk. ${ }^{4}$ Other data indicate SSRI treatment may decrease procollagen type $1 \mathrm{~N}$-terminal propeptide, a peripheral marker of bone formation. ${ }^{5}$ Both SSRIs and serotonin-norepinephrine reuptake inhibitors (SNRIs) have been associated with lower cortical bone mineral density (BMD). ${ }^{6}$ Table $2^{7,8}$ (page 47 ) details the relative affinity of select antidepressants for the serotonin transporter.

Both serotonergic antidepressants and depression have been associated with decreased BMD and increased fracture risk. ${ }^{1,9}$ Behavioral aspects of depression, such as inadequate nutrition or physical inactivity, overlap with risk factors for poor bone health. In addition, elevated levels of circulating cortisol and proinflammatory cytokines in patients with depressive symptoms may contribute to decreased bone mass. ${ }^{10,11}$ Modifiable risk factors for osteoporosis and fractures include low calcium and vitamin D intake, low body weight, and a sedentary lifestyle. Nonmodifiable risk factors include advancing age, female sex, Asian or White ethnicity, malabsorptive conditions, and chronic corticosteroid use. ${ }^{12}$

\section{What the evidence says}

Evidence for the correlation between fractures and serotonergic antidepressant use is mixed. One meta-analysis found a significant association between SSRIs and fractures, suggesting a 1.62-fold increased risk. ${ }^{13}$ Another meta-analysis investigated SSRIs and SNRIs and the risk of fracture. ${ }^{14}$ The SSRIs had a 1.67-fold increased risk; however, a lack of studies prohibited making conclusions about SNRIs. The number needed to harm was calculated at 85,46 , and 19 with 1,2, and 5 years of SSRI exposure, respectively. A third meta-analysis found increased fracture risk related to depression and reported a hazard ratio of 1.26 after adjusting for confounders. ${ }^{9}$ This analysis suggests depression affects fracture risk and may limit the interpretation of causation from SSRI use. Studies 


\section{Affinity for serotonin and norepinephrine transporters by select antidepressants}

\begin{tabular}{|c|c|c|}
\hline Antidepressant & Serotonin transporter & $\begin{array}{l}\text { Norepinephrine } \\
\text { transporter }\end{array}$ \\
\hline \multicolumn{3}{|c|}{ Selective serotonin reuptake inhibitors } \\
\hline Citalopram & +++ & - \\
\hline Escitalopram & +++ & - \\
\hline Fluoxetine & +++ & - \\
\hline Fluvoxamine & +++ & - \\
\hline Paroxetine & +++ & + \\
\hline Sertraline & +++ & - \\
\hline \multicolumn{3}{|c|}{ Serotonin-norepinephrine reuptake inhibitors } \\
\hline Duloxetine & ++ & ++ \\
\hline Levomilnacipran & ++ & ++ \\
\hline Venlafaxine & ++ & + \\
\hline \multicolumn{3}{|c|}{ Tricyclic antidepressants } \\
\hline Amitriptyline & ++ & + \\
\hline Clomipramine & +++ & + \\
\hline Desipramine & + & +++ \\
\hline Doxepin & + & + \\
\hline Imipramine & ++ & + \\
\hline Nortriptyline & + & ++ \\
\hline \multicolumn{3}{|c|}{ Other antidepressants } \\
\hline Bupropion & - & $-1+$ \\
\hline Trazodone & + & - \\
\hline Vortioxetine & +++ & + \\
\hline \multicolumn{3}{|l|}{$\begin{array}{l}+++ \text { high affinity } \\
++ \text { : moderate affinity } \\
+: \text { mild affinity } \\
\text {-: minimal to no affinity }\end{array}$} \\
\hline Source: References 7,8 & & \\
\hline
\end{tabular}

included in these meta-analyses had significant heterogeneity.

The effect of SSRIs vs non-SSRIs on BMD also has been studied. The SSRIs were associated with significantly reduced BMD of the lumbar spine but not the total hip or femoral neck as compared to non-SSRIs; however, this BMD loss was not examined in relation to the presence of fractures. Older patients had more pronounced bone loss. ${ }^{15}$ Conversely, another meta-analysis examined BMD in women receiving SSRIs or tricyclic antidepressants. ${ }^{10}$ Neither medication class was associated with lower BMD at measured locations, including lumbar spine, femoral neck, and total hip. This analysis was limited by the lack of available trials; only 4 were included.

Other recent research has continued to explore the relationship between antidepressants and fracture in various patient populations. In a study of patients receiving maintenance dialysis treatment, short- and long-term SSRI use increased hip fracture risk. The authors speculated that short-term risk may be mediated by adverse effects that increase fall risk (eg, hyponatremia, orthostasis), whereas long-term risk may be influenced by changes in bone homeostasis. ${ }^{16}$ In two 6-month analyses of fluoxetine

\section{Clinical Point \\ Both SSRIs and SNRIs have been associated with lower cortical bone mineral density}




\section{Clinical Point}

\section{The risk of fracture is likely multifactorial, and includes risk from serotonergic antidepressant use and from depression}

\section{Related Resources}

- Cosman F, de Beur SJ, LeBoff MS, et al. Clinician's guide to prevention and treatment of osteoporosis. Osteoporos Int. 2014;25(10):2359-2581.

- Dodd S, Mitchell PB, Bauer M, et al. Monitoring for antidepressant-associated adverse events in the treatment of patients with major depressive disorder: an international consensus statement. World J Biol Psychiatry. 2018;19(5):330-348.

- Fernandes BS, Hodge JM, Pasco JA, et al. Effects of depression and serotonergic antidepressants on bone: mechanisms and implications for the treatment of depression. Drugs Aging. 2016;33(1):21-25

- US National Library of Medicine. DailyMed. https:// dailymed.nlm.nih.gov/dailymed

Drug Brand Names

Amitriptyline - Elavil Amlodipine $\cdot$ Norvasc Aripiprazole - Abilify Bupropion - Wellbutrin Citalopram - Celexa Clomipramine - Anafranil Desipramine $\cdot$ Norpramin Doxepin · Silenor, Sinequan Duloxetine - Cymbalta Escitalopram • Lexapro Fluoxetine - Prozac Fluvoxamine - Luvox

Imipramine $\cdot$ Tofranil
Levomilnacipran $\cdot$ Fetzima
Loratadine $\cdot$ Claritin
Mirtazapine $\cdot$ Remeron
Nortriptyline $\cdot$ Pamelor
Paroxetine $\cdot$ Paxil
Risedronate $\cdot$ Actonel
Sertraline $\cdot$ Zoloft
Teriparatide $\cdot$ Forteo
Trazodone $\cdot$ Desyrel
Venlafaxine $\cdot$ Effexor
Vortioxetine $\cdot$ Trintellix

treatment in patients following an acute stroke, fluoxetine increased the risk of bone fractures. ${ }^{17,18}$ Finally, in women with osteoporosis receiving risedronate or teriparatide, in both groups a higher fracture risk was observed for patients who were also receiving an SSRI or SNRI. ${ }^{19}$

\section{Monitor BMD and educate patients about bone health}

Available literature has not identified any clear risk factors for fracture with SSRI use. Guidelines suggest monitoring BMD in patients with risk factors for osteoporosis, if clinically indicated, as well as monitoring BMD in those receiving long-term antidepressant treatment. ${ }^{20-22}$ Educate patients on strategies that promote optimal bone health, such as consuming a balanced diet that meets the recommended dietary allowance of calcium, vitamin D, and limits soda consumption. Teach patients to avoid tobacco and excessive alcohol use because both adversely impact BMD. Maintaining a healthy weight, physical activity, and adequate sleep also support bone health. ${ }^{11}$ Instruct patients receiving antidepressants to report unexplained bone pain, tenderness, swelling, or bruising because these symptoms may be indicative of fracture.

\section{CASE CONTINUED}

Mrs. D's age, sex, and depression place her at higher risk of fracture. Paroxetine is the only SSRI that has bone fracture listed as a precaution in its labeling. ${ }^{23}$ In addition, it is the most anticholinergic SSRI and may have contributed to her fall. Switching to bupropion by cross titration may benefit Mrs. D because bupropion is not serotonergic. Little data exist regarding the effects of bupropion on bone. Her prescriber monitors Mrs. D's BMD periodically, and educates her on dietary considerations. He also recommends calcium, 1,200 mg/d, and vitamin D, $800 \mathrm{lU} / \mathrm{d}$, to help prevent fractures, ${ }^{24}$ and that she continue physical therapy exercises and increase physical activity as tolerated.

\section{References}

1. Fernandes BS, Hodge JM, Pasco JA, et al. Effects of depression and serotonergic antidepressants on bone: mechanisms and implications for the treatment of depression. Drugs Aging. 2016;33(1):21-25

2. Lavoie B, Lian JB, Mawe GM. Regulation of bone metabolism by serotonin. Adv Exp Med Biol. 2017;1033:35-46.

3. Berger M, Gray JA, Roth BL. The expanded biology of serotonin. Annu Rev Med. 2009;60:355-366

4. Hodge JM, Wang Y, Berk M, et al. Selective serotonin reuptake inhibitors inhibit human osteoclast and osteoblast formation and function. Biol Psychiatry. 2013;74(1):32-39.

5. Kumar M, Jiloha RC, Kataria D, et al. Effect of selective serotonin reuptake inhibitors on markers of bone loss. Psychiatry Res. 2019;276:39-44

6. Agarwal S, Germosen C, Kil N, et al. Current anti-depressant use is associated with cortical bone deficits and reduced physical function in elderly women. Bone. 2020;140:115552.

7. DeBattista C. Antidepressant agents. In: Katzung BG, ed. Basic and clinical pharmacology. 14th ed. McGraw-Hill; 2018.

8. Kasper S, Pail G. Milnacipran: a unique antidepressant? Neuropsychiatr Dis Treat. 2010;6(Suppl 1):23-31.

9. Wu Q Liu B, Tonmoy S. Depression and risk of fracture and bone loss: an updated meta-analysis of prospective studies. Osteoporos Int. 2018;29(6):1303-1312.

10. Schweiger JU, Schweiger U, Hüppe $M$, et al. The use of antidepressant agents and bone mineral density in women: a meta-analysis. Int J Environ Res Public Health. 2018;15(7):1373

11. Rizzoli R, Cooper C, Reginster JY, et al. Antidepressant medications and osteoporosis. Bone. 2012;51(3):606-613.

12. Rice JN, Gillett CB, Malas NM. The impact of psychotropic medications on bone health in youth. Curr Psychiatry Rep. 2018;20(11):104.

13. Kumar M, Bajpai R, Shaik AR, et al. Alliance between selective serotonin reuptake inhibitors and fracture risk: an updated systematic review and meta-analysis. Eur J Clin Pharmacol. 2020;76(10):1373-1392. 
14. Khanassov V, Hu J, Reeves D, et al. Selective serotonin reuptake inhibitor and selective serotonin and norepinephrine reuptake inhibitor use and risk of fractures in adults: a systematic review and meta-analysis. Int J Geriatr Psychiatry. 2018;33(12):1688-1708.

15. Zhou C, Fang L, Chen Y, et al. Effect of selective serotonin reuptake inhibitors on bone mineral density: a systematic review and meta-analysis. Osteoporos Int. 2018;29(6):1243-1251.

16. Vangala C, Niu J, Montez-Rath ME, et al. Selective serotonin reuptake inhibitor use and hip fracture risk among patients on hemodialysis. Am J Kidney Dis. 2020;75(3):351-360.

17. Hankey GJ, Hackett ML, Almeida OP, et al. Safety and efficacy of fluoxetine on functional outcome after acute stroke (AFFINITY): a randomised, double-blind, placebo-controlled trial. Lancet Neurol. 2020;19(8):651-660.

18. Lundström E, Isaksson $E$, Näsman $P$, et al. Safety and efficacy of fluoxetine on functional recovery after acute stroke (EFFECTS): a randomised, double-blind, placebo-controlled trial. Lancet Neurol. 2020;19(8):661-669.

19. Kendler DL, Marin F, Geusens P, et al. Psychotropic medications and proton pump inhibitors and the risk of fractures in the teriparatide versus risedronate VERO clinical trial. Bone. 2020;130:115113.

20. Dodd S, Mitchell PB, Bauer M, et al. Monitoring for antidepressant-associated adverse events in the treatment of patients with major depressive disorder: an international consensus statement. World J Biol Psychiatry. 2018;19(5): 330-348.

21. American Psychiatric Association. Practice guideline for the treatment of patients with major depressive disorder. Published October 2010. Accessed February 8, 2021. https:// psychiatryonline.org/pb/assets/raw/sitewide/practice_ guidelines/guidelines/mdd.pdf

22. Agacayak KS, Guler R, Ilyasov B. Evaluation of the effect of long-term use of antidepressants in the SSRI group on bone density with dental volumetric tomography. Drug Des Devel Ther. 2019;13:3477-3484

23. US National Library of Medicine. DailyMed. Accessed February 8, 2021. https://dailymed.nlm.nih.gov/dailymed

24. Cosman F, de Beur SJ, LeBoff MS, et al. Clinician's guide to prevention and treatment of osteoporosis. Osteoporos Int 2014;25(10):2359-2581.

\section{Clinical Point}

\section{Educate patients} on modifiable risk factors and discuss calcium and vitamin $D$ requirements, diet, and exercise 